\title{
Seroepidemiology and Gender Related Differences in Laboratory Characteristics of Dengue Virus Infection: A Hospital Based Study, Bhopal
}

\author{
Dr.Shashwati Nema ${ }^{1}$, Dr.Amit Deol ${ }^{2}$, Dr.Kiran Tripathi ${ }^{3}$, Dr.V.K.Ramnani ${ }^{4}$ \\ ${ }^{I}$ (Associate Professor,Department of Microbiology,L.N.Medical College \& J.K.Hospital,Bhopal(M.P.) India) \\ ${ }^{2}$ (Intern, L.N.Medical College \& J.K.Hospital,Bhopal (M.P.) India) \\ ${ }_{3}^{3}$ (Professor,Department of Microbiology,L.N.Medical College \& J.K.Hospital,Bhopal(M.P.) India) \\ ${ }^{4}$ (Professor \& Head, Department of Microbiology, L.N.Medical College \& J.K.Hospital, Bhopal (M.P.) India)
}

\begin{abstract}
:
Introduction: Data regarding gender related differences in serological and haematological findings of dengue infection is lacking in Indian settings especially in Central part of India where dengue is endemic.

Objectives: To study seroepidemiology and association of serological and haematological findings with gender in dengue seopositive patients.

Methods: 1071 dengue suspected patients attending to hospital from $1^{\text {st }}$ January 2014 to $31^{\text {st }}$ December 2015 were included. Their serum samples were tested for NS1 antigen and IgM and IgG antibodies by immunochromatographic test. Total leucocytes count (TLC) and platelet counts of seropositive patients were noted. Association of laboratory findings were correlated with gender by using Chi-square test and P value was obtained.

Results and Discussion: 16.43\% samples were found to be seropositive with Male:Female ratio 1:0.76. Maximum seropositivity was detected in 21-30 years. $69.31 \%$ were primary and $17.04 \%$ seropositive cases were labelled as secondary dengue infection. $13.63 \% \operatorname{Ig} M+\operatorname{Ig} G$ positive samples couldn't be classified. Thrombocytopenia and and leucopoenia was detected in 75(42.61\%) and 69(39.20\%) dengue seropositive cases respectively. No significant association was found in haematological findings with gender $(P>0.05)$. Conclusions: The current study found a consistent pattern of male predominance and young age. High index of suspicion of severe dengue fever should be maintained in all patients irrespective of gender.
\end{abstract}

Keywords:Dengue, Gender, Leucopoenia, Seroepidemiology, Thrombocytopenia

\section{Introduction}

Dengue is caused by a positive stranded RNA virus of the flaviviridae family with four distinct serotypes (dengue 1 to 4 ) that are related antigenically. ${ }^{[1]}$ It is estimated that approximately 2.5 billion people are at risk of dengue infection with 50 million infections occurring annually worldwide. ${ }^{[2]}$ Dengue viral infection is endemic in the Indian subcontinent affecting 35 states/UTs including Madhya Pradesh. ${ }^{[3]}$

The spectrum of Dengue infection may range from asymptomatic infection to undifferentiated fever, Dengue fever (DF), Dengue Haemorrhagic fever (DHF) or Dengue Shock Syndrome (DSS).Recovery from infection provides lifelong immunity against that serotype but confers only partial and transient protection against subsequent infection by the other three serotypes. Secondary infection with a serotype different from that causing primary infection may lead to DHF and DSS which can be fatal. ${ }^{[1]}$

Diagnosis of primary dengue is made by the detection of IgM anti-DENV antibodies which appear 5-7 days after the onset of illness and persist for 2-3 months whereas a secondary infection is characterized by production of $\operatorname{IgG}$ antibodies and a weak IgM response ${ }^{[2]}$ The diagnostic methods currently available are viral isolation, viral RNA detection by reverse transcriptase PCR (RT-PCR) or detection of dengue virus specific IgM antibodies by enzyme linked immunosorbent assay (MAC-ELISA) and/or the rapid dengue immunochromatographic test(ICT) ${ }^{[2]}$ Simple and rapid ICT with the detection of NS1 antigen, IgM/IgG antibodies provide opportunities for point-of-care diagnosis especially in many dengue endemic settings, where laboratory diagnostic resources are limited. ${ }^{[4]}$

Previous studies across the world have reported gender related differences in serological and haematological findings of dengue infection. ${ }^{[5-6]}$ However, data regarding this aspect of dengue fever is lacking in Indian settings especially in Central part of India where dengue is endemic. In the absence of vaccines and specific treatment for the DF, prevention and control of the disease mainly depends upon effective vector control measures based on the epidemiological surveillance that provides reliable estimate of the disease. ${ }^{[7]} \mathrm{In}$ view of this, the present study was designed to study epidemiology of dengue infection in and around Bhopal 
based on serological parameter and to study association of serological and haematological findings with gender in dengue seopositive cases.

\section{Materials \& Methods}

2.1) Type of study: Cross sectional study

2.2) Study period: 1st January 2014 to $31^{\text {st }}$ December 2015 (24 Months)

2.3) Specimen collection: Blood sample was collected from patients presenting to our hospital with dengue like illness for which dengue serology was requested. About 2-3 ml of blood was collected using strict aseptic precautions.

2.4) Specimen processing: Serum was separated by standard methods and tested simultaneously for NS1 antigen and IgM and IgG anti-dengue antibodies by ICT (SD Bioline Dengue Duo rapid test). The instructions of the manufacturers were meticulously followed while performing the tests and results were interpreteted.

2.5) Haematological parameters: Platelet count and Total Leucocyte Count (TLC) of seropositive patients were noted. Thrombocytopenia was defined as a platelet count of $<100,000 / \mu L$ and Leucopenia was defined as a leucocyte count of $<5000 / \mu \mathrm{L}^{[2]}$

2.6) Serological classification of Primary and Secondary dengue infection: ${ }^{[2]}$

NS1,NS1+IgM,IgM positive patients were labelled as primary while $N S 1+\operatorname{Ig} M+\operatorname{Ig} G, N S 1+\operatorname{Ig} G, \operatorname{Ig} G$ positive patients were labelled as secondary dengue infection. IgM+IgG positive patients couldn't be classified as ELISA was not done to assess the ratio of IgM/IgG.

2.7) Statistical analysis:

Associations of serological and haematological findings were correlated with gender by using Chi-square test. Statistical significance was defined as $\mathrm{P}$ value $<0.05$.

\section{Results}

Total 1071 blood samples were received for dengue serology during study period. Out of which, 176 samples $(16.43 \%)$ were found to be positive for one or more serological parameter. Among the dengue seropositive cases, the proportion of males was higher giving male: female ratio (M: F) ratio 1:0.76. However, this difference was not found to be statistically significant $(\mathrm{P}=0.55)$ [Table 1].

Table 1: Genderwise distribution of Total Samples and Seropositive Samples

\begin{tabular}{|c|c|c|}
\hline Gender & $\begin{array}{c}\text { Total Samples } \\
\mathbf{n}(\boldsymbol{\%})\end{array}$ & $\begin{array}{c}\text { Positive samples } \\
\mathbf{n}(\boldsymbol{\%})\end{array}$ \\
\hline Male & $634(59.19)$ & $100(15.77)$ \\
\hline Female & $437(40.80)$ & $76(17.39)$ \\
\hline Total & $1071(100)$ & $176(16.43)$ \\
\hline P value & - & $0.5^{*}$ \\
\hline
\end{tabular}

* Nonsignificant

Maximum seropositivity i.e 48 (27.27\%) was detected in 21-30 years followed by 11-20 years of age group 46 (26.13\%) [Fig.1].

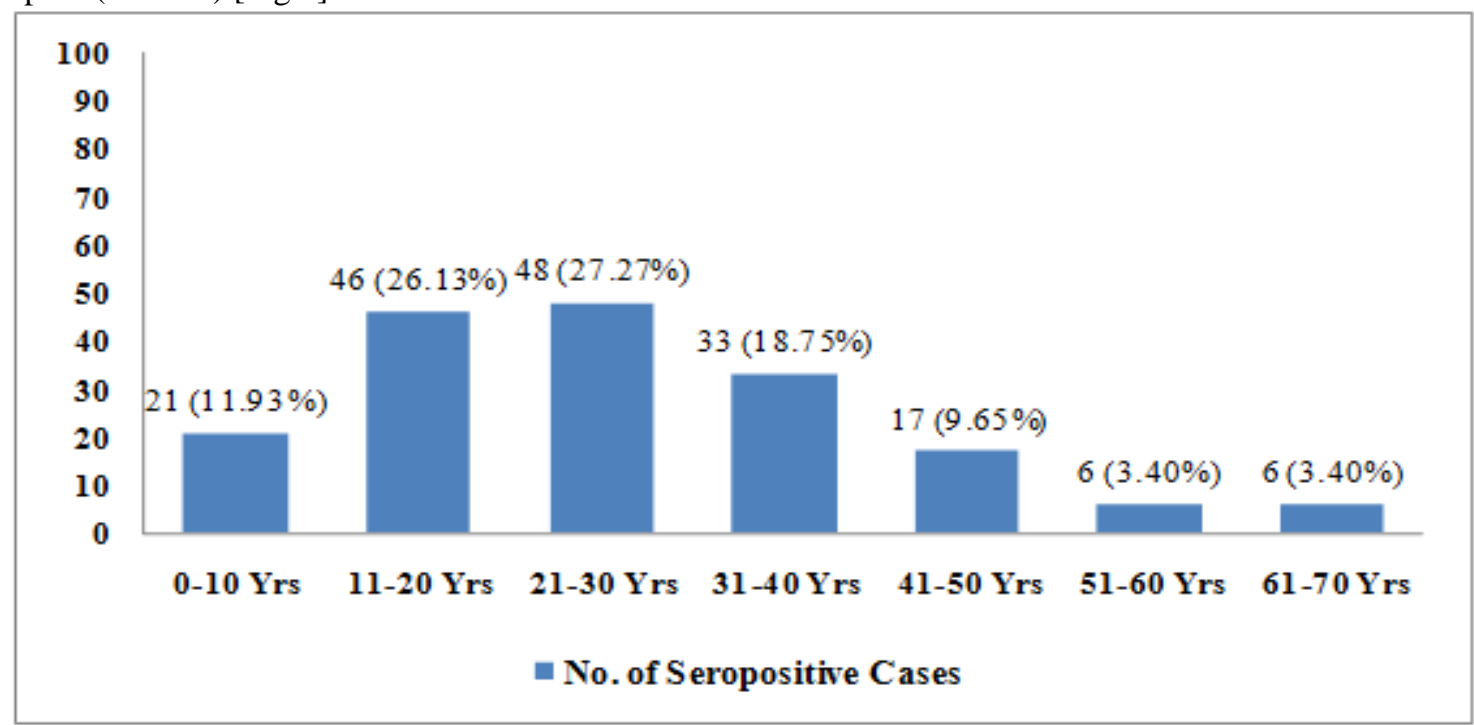

Figure 1: Agewise distribution of seropositive cases 
NS1 Antigen was detected in majority of 102 (57.95\%) dengue seropositive cases [Fig. 2].

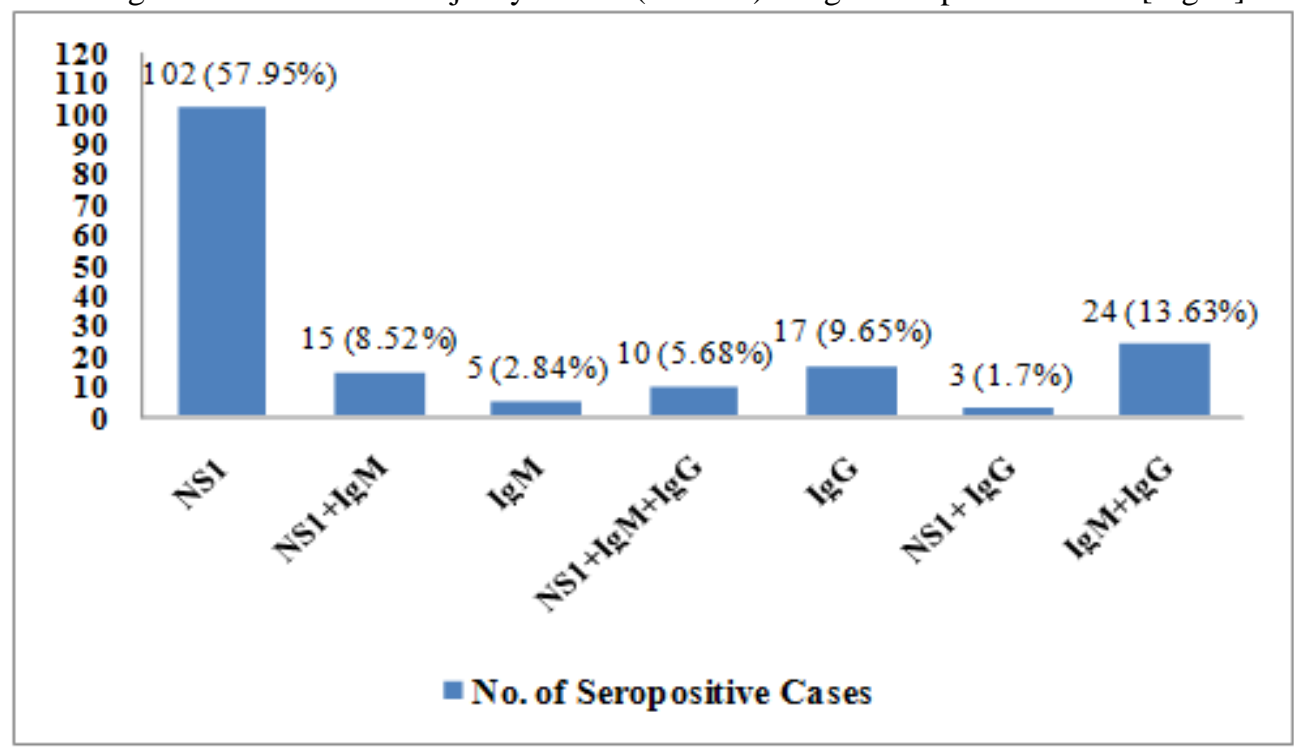

Figure 2: Distribution of serological parameters in dengue seropositive cases

$122(69.31 \%)$ were primary and $30(17.04 \%)$ seropositive cases were labelled as secondary dengue infection. $24(13.63 \%)$ IgM+IgG positive samples couldn't be classified [Table 2]. No significant association was found in primary and secondary dengue infection with gender $(\mathrm{P}=0.6)$ [Table 3 ].

Table 2: Distribution of Primary and Secondary dengue cases based on serology

\begin{tabular}{|c|c|c|c|}
\hline & Primary Infection & Secondary Infection & Not Classified \\
\hline $\begin{array}{c}\text { Serological Parameters } \\
\text { (n) }\end{array}$ & $\begin{array}{ll}\text { NS1 } & (102) \\
\text { NS1 +IgM } & (15) \\
\text { IgM } & (05)\end{array}$ & $\begin{array}{l}\text { NS1+IgM+IgG (10) } \\
\text { IgG } \\
\text { NS1+IgG }\end{array}$ & $\operatorname{IgM}+\operatorname{IgG}(24)$ \\
\hline Total Positivity n (\%) & $122(69.13 \%)$ & $30(17.04 \%)$ & $24(13.63 \%)$ \\
\hline
\end{tabular}

Thrombocytopenia was detected in $75(42.61 \%)$ while Leucopoenia was detected in 69(39.20\%) dengue seropositive cases. No significant association was found in haematological findings with gender $(\mathrm{P}$ $>0.05$ ) [Table 3].

Table 3: Genderwise distribution of laboratory findings

\begin{tabular}{|c|c|c|c|c|c|c|}
\hline Gender & $\begin{array}{l}\text { Total } \\
\text { Samples } \\
\text { n (\%) }\end{array}$ & $\begin{array}{l}\text { Positive } \\
\text { samples } \\
\text { n(\%) }\end{array}$ & $\begin{array}{l}\text { Primary } \\
\text { dengue } \\
\text { Infection } \\
n(\%)\end{array}$ & $\begin{array}{l}\text { Secondary } \\
\text { dengue } \\
\text { Infection } \\
n(\%)\end{array}$ & $\begin{array}{l}\text { Platelet } \\
\text { Count < } \\
100,000 / \mu \mathrm{l} \\
\text { n }(\%)\end{array}$ & $\begin{array}{l}\text { Total } \\
\text { leucocyte } \\
\text { count }< \\
5000 / / \mu \mathrm{l} \\
\mathrm{n}(\%)\end{array}$ \\
\hline Male & $\begin{array}{l}634 \\
(59.19) \\
\end{array}$ & $\begin{array}{l}100 \\
(15.77) \\
\end{array}$ & $\begin{array}{l}67 \\
(67)\end{array}$ & $\begin{array}{l}15 \\
(15)\end{array}$ & $\begin{array}{l}42 \\
(42)\end{array}$ & $\begin{array}{l}40 \\
(40)\end{array}$ \\
\hline Female & $\begin{array}{l}437 \\
(40.80)\end{array}$ & $\begin{array}{l}76 \\
(17.39)\end{array}$ & $\begin{array}{l}55 \\
(72.36)\end{array}$ & $\begin{array}{l}15 \\
(19.73)\end{array}$ & $\begin{array}{l}33 \\
(43.4)\end{array}$ & $\begin{array}{l}29 \\
(38.15)\end{array}$ \\
\hline$P$ value & - & 0.5 & 0.6 & 0.6 & 0.4 & 0.3 \\
\hline $\begin{array}{l}\text { Statistical } \\
\text { Significance }\end{array}$ & - & Nonsignificant & Nonsignificant & Nonsignificant & Nonsignificant & Nonsignificant \\
\hline
\end{tabular}

\section{Discussion}

Dengue is known for its serious life threatening complications. Early laboratory diagnosis of acute dengue virus infections is important to provide appropriate treatment of the patient and to prevent potential dengue outbreak.

In the present study, dengue seropositivity was found to be $16.43 \%$ [Table 1] which is comparable to the rate reported by Shaikh Khalida et al $(18.5 \%) .{ }^{[8]}$ In other similar Indian studies, Saini S et al ${ }^{[9]}$ in Loni, Maharashtra found $30.6 \%$ positivity rate while N. Bhattacharya et al ${ }^{[10]}$ in Kolkata, West Bengal reported $38.3 \%$ dengue seropositivity. The reason for variation in dengue positivity may be related to history of herd immunity, introduction of new serotype or geographical variations in a particular area. 
Understanding male -female differences in infection rates and severity of disease is important for public health control programme. In the present study, the proportion of males was observed to be higher than females giving male: female ratio (M: F) ratio 1:0.76 [Table 1]. Three independent studies from epidemics in India done by Ray et $\mathrm{al}^{[11]}$, Agarwal et $\mathrm{al}^{[12]}$ and Wali et $\mathrm{al}^{[13]}$ found nearly twice the number of male patients infected with dengue compared to females M:F being 1:0.57, 1.9:1 and 2.5:1 respectively. Male predominance may be attributed to their more outdoor exposure to transmitting agent. An analytical study was conducted in Singapore from 1998 to 2000.The study concluded that predominance of male cases were likely due to greater male exposures to dengue carrying mosquitoes during daytime hours either at the work place or while travelling to and from work. ${ }^{[14]}$ However, Yew et al ${ }^{[15]}$ did not find movement history as a contributing factor for male predominancy and suggested male - female differences in the use of health services. It has been established earlier that many Asian countries lower disease incidence in women may be a statistical artefact related to lower reporting and care seeking for women. In our study, difference in dengue seropositivity among males and females was not found to be statistical significant $(\mathrm{P}=0.55)$ [Table 1]. Well designed studies considering both biological and social factors that influence the disease patterns in the community are required to determine the sex differences.

In Southeast Asia, dengue infection is predominantly a childhood disease and is an important cause of paediatric hospitalization. However, age shift from paediatric age group to young adults have been observed in different surveillance reports. ${ }^{[16]}$ Hospital based studies have similarly reported increasing infection rates among adults mentioning that it is contrary to the popular belief that dengue is paediatric disease. ${ }^{[13,17]}$ Results of the present study also confirmed this notion [Fig. 1]. The trend for increased incidence among young adults has important implications for control and prevention.

NS1 Ag circulates uniformly in all serotypes of dengue virus and it circulates at high level during the first few days of illness. NS1 Ag level varies from $0.04-2 \mu \mathrm{m} / \mathrm{ml}$ in acute phase serum samples, to only $0.04 \mu \mathrm{g} / \mathrm{ml}$ or even less in convalescent phase serum. This is the reason for its high detection rate in acute phase sera. ${ }^{[18]}$ In this study, only NS1 antigen was positive in $57.95 \%$ of the cases [Fig. 2]. These cases would have been failed to be detected at that time if only antibody based assays are used for the laboratory diagnosis of dengue. Similar findings were observed in other studies ${ }^{[17,20]}$ in which the sensitivity of detection of dengue infection increased when both antigen and antibody based assays were used as diagnosis

The differentiation between primary and secondary dengue infection is important as secondary dengue infection are more commonly associated with DHF and DSS. ${ }^{[1]}$ Differentiation requires detection of IgM and/or IgG antibody. During acute phase of the disease, the presence of DENV IgM antibody alone suggest primary infection and the concomitant detection of DENV IgM and IgG antibodies is suggestive of secondary infection. ${ }^{[2]}$ In the present study, using ICT assay, primary infection cases were found to be $122(69.31 \%)$ and secondary infection cases were $30(17.04 \%) .14(13.63 \%)$ cases couldn't be classified as ELISA was not done to assess the ratio of $\mathrm{IgM} / \mathrm{IgG}$ [Table 2]. Similar observations have been reported by Kidwai AA et al ${ }^{[19]}$ and Rashmi KS et $\mathrm{al}^{[20]}$. Though incidence of primary and secondary dengue infection was observed to be higher in females, this difference was not found to be statistically significant (P value: 0.6) [Table 3].

Myelosuppression in DF leads to thrombocytopenia and leucopenia. 75(42.61\%) dengue seropositive cases were detected to have thrombocytopenia in our study [Table 3]. Soumy K et al ${ }^{[17]}$ and Kulkarni RD et al ${ }^{[21]}$ proved a significant association between thrombocytopenia and dengue infection. In the present study, leucopenia was detected in 69 (39.20\%) seropositive cases [Table 3]. In two independent hospital based studies $[6,17]$, leucopenia was found in approximately $60 \%$ of dengue seropositive cases. Thus, haematological findings can play a complementary role in prompting the suspicion and facilitating the timely diagnosis and management of dengue even before availability of serological test results. Chakravarti et $\mathrm{al}^{[6]}$ reported significant association of thrombocytopenia and leucopenia with females as compared to males. However, in the present study no significant association was found in haematological findings with gender ( $P$ value $>0.05$ ) [Table 3 ].

There are certain limitations of our study. Since it is a hospital based study, it may represent only the tip of the iceberg in the overall pattern of dengue infection. In addition, ELISA and molecular method of higher sensitivity and specificity were not used.

\section{Conclusions}

The current study found a consistent pattern of male predominance and young age in the reported incident cases of dengue fever. This study re-emphasizes the need for the inclusion of NS1 antigen detection based assay for the early and accurate diagnosis of dengue virus infection. It is recommended to test dengue specific NS1 antigen and $\operatorname{IgM}$ and $\mathrm{IgG}$ anti dengue antibodies simultaneously for categorizing infection as primary or secondary for effecting monitoring and treatment. Reduced platelet count and TLC can be used as a cost-effective laboratory investigation prompting a high suspicion of dengue infection especially in resource poor setting where serological tests may not be available. High index of suspicion of DHF and DSS should be maintained in all patients irrespective of gender. 


\section{Acknowledgement}

We are thankful to department of Pathology,L.N.Medical College and J.K.Hospital,Bhopal for providing data of Platelet count and Total Leucocyte Count (TLC) of Dengue seropositive patients for our study.

\section{References}

[1]. John T. Roehrig and Duane J. Gubler, Flaviviruses in Brian WJ Mahy and Wolker Ter Meulen,Topley and Wilson's Microbiology and Microbial Infections. Virology Vol.2, 10th Edition (UK: John Wiley\& Sons Ltd., 2009)1000-01.

[2]. World Health Organisation/Research and Training in Tropical Diseases (TDR). Dengue: Guidelines for diagnosis, treatment, prevention and control (New edition). Geneva, Switzerland: Chapter 4, Laboratory diagnosis and diagnostic tests; WHO/HTM/NTD/DEN/2009:91-110.

[3]. Annual report 2014-15, Government of India,National Vector Borne disease control programme, Directorate general of health services ,Ministry of health \& family welfare

[4]. Blacksell SD. Commercial Dengue Rapid Diagnostic Tests for Point-of-Care Application: Recent Evaluations and Future Needs? J Biomed Biotechnol. 2012;2012:Article ID 151967 (Available from https://www.hindawi.com/journals/bmri/2012/151967/ as accessed on 12/11/2016)

[5]. Kosasih H, Alisjahbana B, Widjaja S, Nurhayati, de Mast Q, Parwati I, et al. The diagnostic and prognostic value of dengue nonstructural 1 antigen detection in a hyper-endemic region in Indonesia. PLoS One 2013;8:e80891

[6]. Chakravarti A, Roy P, Malik S, Siddiqui O, Thakur P. A study on gender-related differences in laboratory characteristics of dengue fever. Indian J Med Microbiol 2016;34:82-4

[7]. Chakravarti A, Matlani M, Kashyap B, Kumar A. Awareness of changing trends in epidemiology of dengue fever is essential for epidemiological surveillance. Indian J Med Microbiol 2012; 30:222-6.

[8]. Shaikh K, Memon KN, Sarah B, Akhtar R, Memon M, Memon S. Dengue fever; an audit of risk factors among patients reporting at a tertiary care hospital in Hyderabad. Professional Med J 2014; 21(3): 455-459.

[9]. Saini S, Kinikar AG, Deorukhkar S, Bhalerao D, Roushani S B. Epidemiology and seropositivity of dengue fever cases in a rural tertiary care hospital of western Maharashtra, India. IJBAR 2013; 04 (07):473-77.

[10]. N Bhattacharya, H Mukherjee, R Naskar, S Taludar, G Das, N Pramanik.Serological diagnosis of dengue in laboratory practice in Kolkata. IJMM 2014, 32(3):277-280.

[11]. Ray G, Kumar V, Kapoor AK, Dutta AK, Batra S. Status of antioxidants and other biochemical abnormalities in children with dengue fever. J Trop Pediatr 1999;45:4-7

[12]. Agarwal R, Kapoor S, Nagar R, Misra A, Tandon R, Mathur A, et al. A clinical study of the patients with dengue hemorrhagic fever during the epidemic of 1996 at Lucknow, India. Southeast Asian J Trop Med Public Health 1999;30:735-40

[13]. Wali JP, Biswas A, Handa R, Aggarwal P, Wig N, Dwivedi SN. Dengue haemorrhagic fever in adults: A prospective study of 110 cases. Trop Doct 1999;29:27-30

[14]. Eong OE. Changing pattern of dengue transmission in Singapore. Dengue Bulletin, 2001, 25:40-44. (Available from: http://apps.searo.who.int/PDOS_DCS/B0223.pdf as accessed on 12/11/2016).

[15]. Yew YW et al. Seroepidemiology of dengue virus infection among adults in Singapore. Annals of the Academy of Medicine, Singapore, 2009, 38:667-275.

[16]. Debarti G, Barbara S. Dengue fever: new paradigms for a changing epidemiology. Emerging Themes in Epidemiology 2005; 2:1 (Available from http://www.ete-online.com/content/2/1/1 as accessed on 12/11/16).

[17]. Kaup S, Sankarankutty J . Seroprevalence and Seasonal Trend of Dengue Virus Infection at a Teaching Hospital in Tumkur, India Sch. J. App. Med. Sci. 2014; 2(3A):922-26.

[18]. Datta S, Wattal C; Dengue NS1 antigen detection:A useful tool in early diagnosis of dengue virus infection. Indian J Med Microbiol., 2010; 28(2):107-110.

[19]. Kidwai AA, Jamal Q, Saher, Mehrunnisa, Farooqi FU, Saleem-Ullah. Serodiagnosis of dengue infection using rapid immunochromatography test in patients with probable dengue infection. J Pak Med Assoc. 2010; 60(11):936-9.

[20]. Rashmi KS, Jagadeesh, Ravikumar KL, Pratibha Malini J, Giridhar Upadhyaya P, Arun Kaushik R. Serological markers prevalence and trend of probable dengue infection at a tertiary care hospital in Bangalore. Journal of Evolution of Medical and Dental Sciences 2013; 2(36): 6968-6976.

[21]. Kulkarni RD, Patil SS, Ajantha GS, Upadhya AK,Kalabhavi AS, Shubhada RM, Shetty PC, Jain PA;Association of platelet count and serological markers of dengue infection-importance of NS1 Antigen. Indin J Med Microbiol., 2011; 29(4): 359-362. 